\title{
Polyphenols extracted from red grape pomace by a surfactant based method show enhanced collagenase and elastase inhibitory activity
}

Article

Accepted Version

Mohd Maidin, N., Michael, N., Oruna-Concha, M. J. and Jauregi, P. (2018) Polyphenols extracted from red grape pomace by a surfactant based method show enhanced collagenase and elastase inhibitory activity. Journal of Chemical Technology and Biotechnology, 93 (7). pp. 19161924. ISSN 0268-2575 doi: https://doi.org/10.1002/jctb.5459 Available at https://centaur.reading.ac.uk/72891/

It is advisable to refer to the publisher's version if you intend to cite from the work. See Guidance on citing.

Published version at: http://dx.doi.org/10.1002/jctb.5459

To link to this article DOI: http://dx.doi.org/10.1002/jctb.5459

Publisher: Wiley

All outputs in CentAUR are protected by Intellectual Property Rights law, including copyright law. Copyright and IPR is retained by the creators or other copyright holders. Terms and conditions for use of this material are defined in the End User Agreement. 


\section{www.reading.ac.uk/centaur}

\section{CentAUR}

Central Archive at the University of Reading

Reading's research outputs online 


\title{
Polyphenols extracted from red grape pomace by a surfactant based method show enhanced collagenase and elastase inhibitory activity
}

$$
\text { Nurmahani Mohd Maidin }{ }^{\mathrm{a}, \mathrm{b}} \text {, Nicholas Michael }{ }^{\mathrm{c}} \text {, Maria Jose Oruna-Concha }{ }^{\mathrm{a}} \text { and Paula }
$$
Jauregia

a Department of Food and Nutrition Sciences, The University of Reading, Reading, United Kingdom

${ }^{\mathrm{b}}$ Department of Food Technology, Faculty of Food Science and Technology, Universiti Malaysia Terengganu, Malaysia

${ }^{\mathrm{c}}$ Chemical Analysis Facility (CAF), Department of Chemistry, Harborne Building, The University of Reading, Reading, United Kingdom

* Tel: +44 (0) 1183788728 Fax: 01189310080 email: p.jauregi@ reading.ac.uk

Short title: Collagenase and elastase inhibitory activity of polyphenols separated by CGA

\begin{abstract}
BACKGROUND: The aim of this study is to separate polyphenols from grape pomace using a surfactant-based separation, Colloidal Gas Aphrons (CGA) and to investigate their inhibitory activity against skin relevant enzymes, collagenase and elastase. Ethanolic (EE) and hot water crude extracts (HWE) were produced first and then the CGA generated using TWEEN20 were applied resulting in polyphenols enriched fractions (CGA-EE and CGA-HWE, ethanol and hot water extracts derived fractions respectively).
\end{abstract}

RESULTS: Both crude extracts inhibited the enzymes in a dose-dependent manner however, further extraction by CGA led to fractions with higher inhibitory efficiency against collagenase. Although gallic acid was the main component of the CGA-HWE, others such as kaempferol must have contributed to its potency which was over six times more than gallic acid's. The 
1 CGA-EE was found to be about four times more efficient than its crude extract and over six

2 times more efficient than gallic acid in collagenase's inhibition; quercetin was the major

3 polyphenol in this fraction.

5 CONCLUSION: It is evident that ethanol and hot water extraction processes led to different

6 polyphenols composition and thus different inhibitory activity against collagenase and elastase.

7 Further separation with CGA increased the inhibitory potency of both extracts against

8 collagenase. Overall the results here showed the potential application of the CGA fractions

9 from grape extracts in cosmetics.

11 Keywords: colloidal gas aphrons, grape pomace, polyphenols, collagenase, elastase

12 Abbreviations: AAAPVN, N-Succ-Ala-Ala-Ala-p-nitroanilide; AOAC; association of 13 analytical communities; CGA, colloidal gas aphrons; ChC; $C$. hystoliticum collagenase Type 14 IA; FALGPA; N-[3-(2-furyl)acryloyl]-Leu-Gly-Pro-Ala; ECM; extracellular matrix; $15 \mathrm{GAE}_{280 \mathrm{~nm}}$, gallic acid equivalents based on total phenol index measure at 280nm; GAE $760 \mathrm{~nm}$, 16 gallic acid equivalents based on Folin index measure at 760nm; PPE; porcine pancreatic 17 elastase.

\section{INTRODUCTION}

Over the past two decades, research on the use of natural products, particularly

21 polyphenols, in beauty products has been active but challenging (1). Polyphenols with a 22 hydroxyl group (-OH) attached to an aromatic benzene ring $\left(\mathrm{C}_{6} \mathrm{H}_{5}-\right)$ naturally occur in plants 23 and are therefore abundant in our diet (eg: vegetables, fruits, nuts, seeds and flowers), and have been extensively studied for their protective health effects against cardiovascular diseases and cancers (2). Moreover, they have been proven to exhibit significant antioxidant activity, as well as a UV protection effect which are very crucial for skin care products formulation (3). 
1 Green tea is the most widely studied plant for its cosmetic applications. Green tea

2 polyphenols extract incorporated in derma gels were found to display significant antioxidant

3 activity and prevent adverse effects of UV radiation by improving the elasticity of the skin

4 (4,5). Catechins and epigalocatechin gallate from green tea and cocoa beans extracts were

5 found to possibly contribute to this effect (5-7). In addition, catechin could stabilise the

6 structure of collagen suggesting the involvement of hydrogen bonding and hydrophobic

7 interactions as major forces in its stabilisation (8). Moreover Sin \& Kim (9) found that the

8 flavonols, particularly quercetin and kaempferol exhibited higher collagenase inhibitory

9 activity than flavones/isoflavones. In a recent study, Wittenauer et al. (10) found that free

10 phenolic acids, particularly gallic acid extracted from grape had the most potent inhibitory

11 activity against both collagenase and elastase. However, it is worth mentioning that the

12 inhibitory concentration of polyphenols varies between studies and samples $(268 \mu \mathrm{M}-$

$131000 \mu \mathrm{M})$; this is partly due to the variations in polyphenols composition. Also the size of

14 polyphenols restricts their permeation into the epidermal and corium layers (11) which could

15 hinder their application in cosmetics.

16 Surfactants are often used in cosmetics products to address the problem with the

17 permeation of the desired molecules. Surfactants in their micellar form can help in the

18 solubilisation of compounds (12) hence increasing its permeation through the skin and

19 promoting absorption by lowering the interfacial tension at the skin surface. The delivery of

20 resveratrol and curcumin has been improved by the presence of surfactants in pig skin (13),

21 and the acceleration of hydrocortisone and lidocaine has been observed on hairless mouse skin

22 by using TWEEN80 (14). Therefore, using a surfactant based extraction method is an

23 advantage as the product is extracted in a media (surfactant solution) that is suitable and

24 possibly optimum for its formulation, which can lead to process simplification. 
1 In our group, we investigated a surfactant based extraction method, Colloidal Gas

2 Aphrons (CGA), for the separation of polyphenols from grape (15). CGA are microbubbles

$3 \quad(10-100 \mu \mathrm{m})$ generated by intense stirring $(>8000 \mathrm{rpm})$ of a surfactant solution above its critical

4 micelle concentration. CGA are composed of an inner core gas surrounded by a thin layer film.

5 The type of surfactant used to generate CGA determines the charge of the outer surface of the

6 layer, which could be positive, negative or non-charged and oppositely or non-charged

7 molecules will adsorb resulting in their effective separation (16).

In the present study the aim was to determine if the extraction of polyphenols by the

9 CGA method led to enhanced in vitro inhibitory activity against Clostridium histolyticum

10 collagenase $(\mathrm{ChC})$ and porcine pancreatic elastase (PPE) enzymes. The relationship between polyphenol composition of the raw and the CGA extracts, and their inhibitory activity were also investigated in order to identify the key polyphenols responsible for these activities. To the best of our knowledge, this is the first study on the potential inhibitory activity of red grape pomace extracts and their CGA fractions against $\mathrm{ChC}$ and PPE.

\section{MATERIALS AND METHODS}

Grape pomace (Barbera) provided by wineries in Nothern Italy was oven dried at $60^{\circ} \mathrm{C}$ until the residual moisture content was $<5 \%$, and milled into particle size of $<2 \mathrm{~mm}$. The phenolic extracts were obtained by ethanol-aqueous extraction using $60 \%(\mathrm{v} / \mathrm{v})$ and hot water extraction at $60^{\circ} \mathrm{C}$ and $100^{\circ} \mathrm{C}$ in a shaking water bath (100rpm) in circular motion for 2 hours and 1 hour, respectively (See Figure 1 for full extraction process). For both extractions, the ratio of solute to solvents used was $1: 8$ according to (17). The extracts were kept at $-20^{\circ} \mathrm{C}$ freezer until further use. Extractions were carried out in triplicate. 
2 (FALGPA), porcine pancreatic elastase (PPE) type III, N-Succ-Ala-Ala-p-nitroanilide

3 (AAAPVN), phenol crystals and BCA reagents were obtained from Sigma (St. Louis, MO).

4 The polyphenols standards used for HPLC analysis and inhibition studies were gallic acid $5(\geq 95 \%)$, caffeic acid ( $\geq 95 \%)$, epicatechin ( $\geq 95 \%)$, p-coumaric acid ( $\geq 95 \%)$, benzoic acid 6 ( $\geq 99.5 \%)$, trans-resveratrol $(\geq 95 \%)$, quercetin $(\geq 95 \%)$, malvidin-3-o-glucoside $(\geq 95 \%)$, 7 cyanidin-3-o-glucoside $(\geq 95 \%)$, petunidin-3-o-glucoside $(\geq 95 \%)$ and delphinidin-3-o8 glucoside ( $\geq 95 \%$ ) from Sigma (St. Louis, MO); and procyanidin (B2 $\geq 90 \%$ ), from Fluka 9 (Buchs, Switzerland). All solvents were of HPLC grade or LC-MS grade.

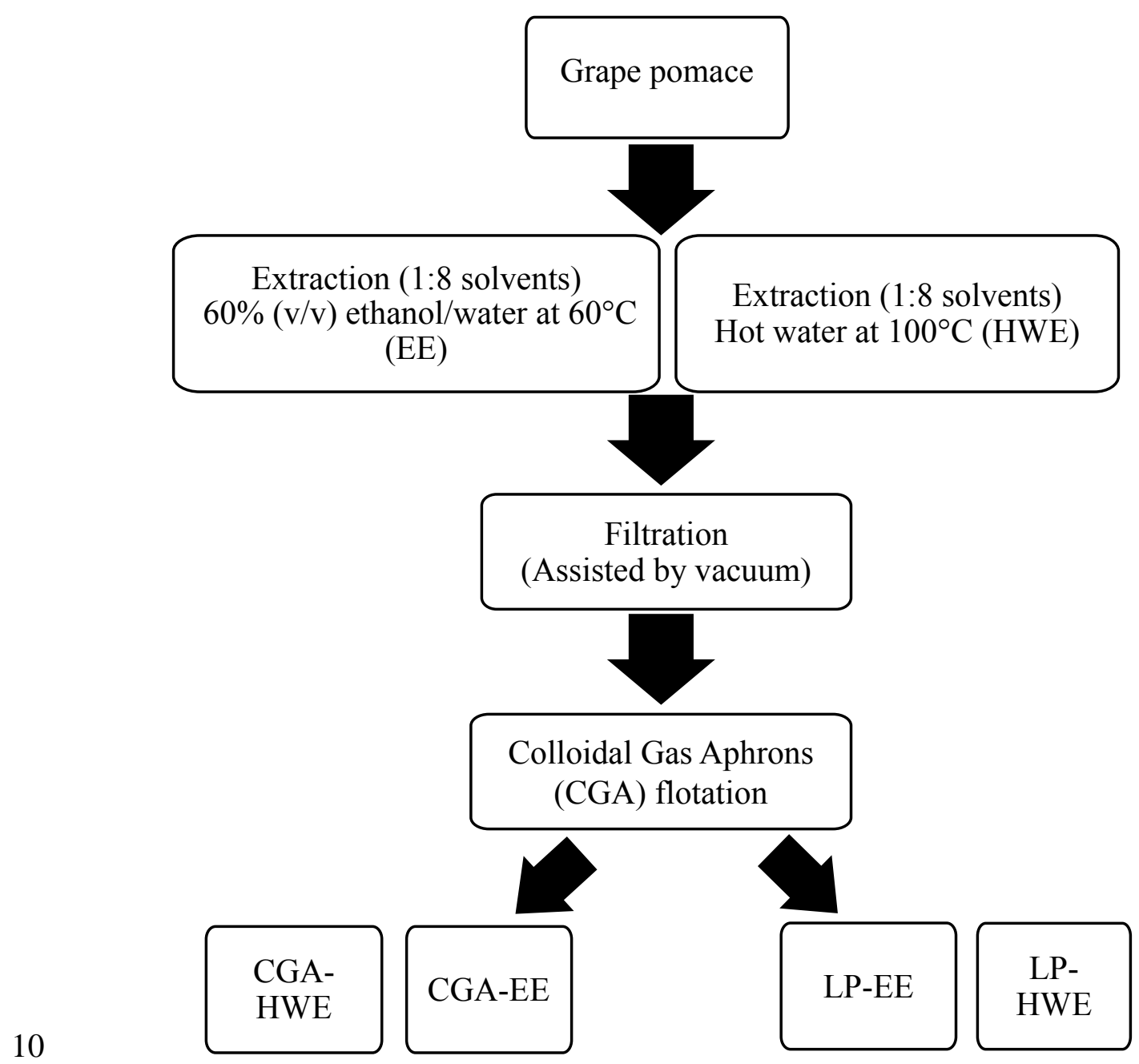

11 Figure 1: Schematic representation of the extraction of polyphenolic compounds present in grape 12 pomace. The whole procedure was performed in triplicate $(n=3)$. EE, ethanol extract, HWE, hot water 13 extract, CGA-EE; Aphron phase of EE, CGA-HWE; Aphron phase of HWE, LP-EE, liquid phase of 14 EE and LP-HWE; liquid phase of HWE 


\section{Characterisation of grape pomace}

\section{Phenolic compounds}

The grape pomace extracts, liquid and CGA fractions recovered were characterised for

4 its total phenolics and anthocyanins. Total phenolics were measured by:

5 (i) direct measurement based on the absorbance reading at $280 \mathrm{~nm}$. Results were expressed by

6 gallic acid equivalents $\left(\mathrm{GAE}_{280 \mathrm{~nm}}\right)$ by means of calibration curve with standard gallic acid

7 ranging from 0-150mg/L (17). (ii) Folin-Ciocalteu method (18). The results were expressed as 8 gallic acid equivalents $\left(\mathrm{GAE}_{760 \mathrm{~nm}}\right)$.

9 Total anthocyanins content was determined by applying the method from AOAC (19).

10 This method is based on the anthocyanins structural transformation that occurs with a change 11 in $\mathrm{pH}$ and commonly referred as $\mathrm{pH}$ differential method. The results were expressed as $\mathrm{mg} / \mathrm{L}$ 12 malvidin-3-glucoside equivalents (ME).

Non-phenolic compounds

Total proteins were quantified according to the bicinchoninic acid assay (BCA) (20). Briefly, $100 \mu \mathrm{l}$ of standard or sample was mixed with $2 \mathrm{~mL}$ of the BCA working reagent (copper sulphate solution:BCA solution at a ratio of 1:50). The mixture was allowed to stand at $37^{\circ} \mathrm{C}$ for 30 mins, and then allowed to cool at room temperature for 5 mins. Finally, the absorbance for each sample/standard was read at $562 \mathrm{~nm}$ within 8 mins with water as a blank. Bovine serum albumin $(0-1.0 \mathrm{mg} / \mathrm{L})$ was used as a standard for protein quantification.

Total sugar content was performed adopting the method from Dubois et al. (21). In test tubes, $0.4 \mathrm{~mL}$ of glucose standard/sample was added followed by $0.2 \mathrm{~mL}$ or $5 \%$ phenol solution.

23 Subsequently, $1 \mathrm{~mL}$ of sulphuric acid was pipetted direct to the solution and vortexed. The mixture was allowed to stand for 20-30mins to cool off. The absorbance of the mixture was 
1 read at 490nm and a calibration curve was constructed with different concentrations (10-

$2100 \mathrm{mg} / \mathrm{L}$ ) of glucose standard. The results were expressed as $\mathrm{mg} / \mathrm{L}$ glucose equivalent.

\section{Determination of polyphenols composition by HPLC}

Separation of the polyphenols was performed using an Agilent HPLC 1100 series system

6 equipped with a degasser, a quaternary pump and a photodiode array detector (Agilent,

7 Waldbronn, Germany) with Chemstation software. The column used was a C18 HiChrom

8 column $(150 \mathrm{~mm} \times 4.6 \mathrm{~mm}$ i.d; $5 \mu \mathrm{m}$ particle size and $100 \AA$ pore size; part no.EXL-121-

$91546 \mathrm{U})$ operated at $25^{\circ} \mathrm{C}$.

The mobile phase consisted of $2 \%$ formic acid (v/v) and $5 \%$ acetonitrile (v/v) in water

(mobile phase A) and 2\% formic acid (v/v) in acetonitrile (mobile phase B) using the following gradient: 5-15\% B (15 mins), 15-30\% B (15 mins), 30-50\% B (10 mins), 50-95\% B (5 mins) and $95-5 \% \mathrm{~B}$ (5 mins), at a flow rate of $1 \mathrm{~mL} / \mathrm{min}$. The total run was $50 \mathrm{mins}$. The pre time of 10 mins was allowed for re-equilibrating. The injection volume was $20 \mu \mathrm{L}$ for pure standards and $100 \mu \mathrm{L}$ for grape extracts. The polyphenols were monitored simultenesouly at $280 \mathrm{~nm}$ (hyroxybenzoic acids and flavanols), 320nm (hydroxycinnamic acids and stilbenes), 365nm (flavonols) and 520nm (anthocyanins).

Identification of polyphenols by LC-MS

The LC-MS analyses were carried out using a Thermo Scientific Accela HPLC with PDA

$21 \mathrm{UV} /$ Vis detector interfaced to a Thermo Scientific LTQ Orbitrap XL with ESI source.

22 Chromatographic separation was carried out using an Ace-5 C18 column; 150 x $2.1 \mathrm{~mm}, 5 \mu \mathrm{m}$ particle, $300 \AA$ A pore (part no. 221.1502). All samples were analysed without dilution and in 10 fold dilution. Dilutions were done in mobile phase A2 buffer $(0.1 \%$ formic acid (v/v) in LC- 
1 MS water). Mobile phase B2 buffer was $0.1 \%$ formic acid (v/v) in acetonitrile. Injections

2 volumes were $20 \mu \mathrm{L}$. The following gradient was used: 0 min 5\% B2; 5-15\% B2 (15mins), 15-

$30 \%$ B2 (15mins), 30-50\% B2 (5mins), 50-95\% B2 (5mins), 95-5\% B2 (5mins) and 5\% B2

4 (10mins), at a flow rate of $200 \mu \mathrm{L} / \mathrm{min}$.

5

The MS parameters were as follow: a standard of caffeic acid was infused into the MS source alongside the HPLC flow at $20 \%$ mobile phase B; using a T-piece the source and transmission settings were optimised for both positive and negative ion modes. The salient settings were as follows: sheath gas flow at 45 , aux gas at 10 , sweep gas at 0 and the capillary temperature was at $300^{\circ} \mathrm{C}$. For the positive mode, the source voltage was $5 \mathrm{Kv}$, capillary voltage was $31 \mathrm{v}$ and tube lens was $125 \mathrm{v}$. For the negative mode, the source voltage was $5 \mathrm{Kv}$, capillary voltage was $-35 \mathrm{v}$ and tube lens was $-90 \mathrm{v}$.

The MS was operated using a Data-dependent acquisition (DDA) method. In brief, an MS1 scan was performed using the Orbitrap detector scanning from 85 to $1000 \mathrm{~m} / \mathrm{z}$ at a resolution of 30,000 storing data in profile. Phthalate $(413.266230 \mathrm{~m} / \mathrm{z})$ was used as lock-mass. Then, MS2 (fragmentation event) was triggered on the most dominant ion found in the MS1 scan. This MS2 was performed in the ion trap, using collision-induced dissociation (CID) and the data was stored as centroid.

Data was analysed using Qual Browser (Xcalibur 2.1) Thermo Scientific. Theoretically, $\mathrm{m} / \mathrm{z}$ was calculated for both the protonated (positive ion mode) and deprotonated (negative ion mode) for each compound. Extracted ion chromatograms (EICs) for these m/z (5ppm mass tolerance) as well as the UV chromatograms were generated at $280 \mathrm{~nm}, 320 \mathrm{~nm}$ and $520 \mathrm{~nm}$. The retention time of the standards from the MS1 scans and the MS2 fragmentation spectra from the standards were compared to the samples (unit resolution mass tolerance). 
When the retention time, parent mass and fragmentation matched the standard, a confident match was determined. In some instances, due to the nature of DDA experiments,

3 the ion of interest was not fragmented in which case only the retention time and parent mass could be used and a less confident match was determined. In the case of phenolics, when there were no standards and hence no retention time available, the fragmentation spectra were referred solely on the match of fragmentation spectra reported in Kammerer et al. (22).

\section{Separation with Colloidal Gas Aphrons (CGA) using 10mM TWEEN20}

In the previous work by our group, it was found that high recovery of polyphenols from grape ethanolic extracts could be obtained by CGA generated with the cationic surfactant Cetyl trimethylammonium bromide (CTAB) and the non-ionic TWEEN20 (15). In the present work, ethanolic and hot water extracts were first obtained from grape pomace (see Figure 1 for full separation process). Hot water extract (HWE) was applied to the CGA for the first time. CGA generated from 10mM TWEEN20 were then applied to each extract based on the optimum conditions found in our previous work eg: the ratio of extract to the CGA was kept constant at 16:1 and the drainage time was kept at $5 \mathrm{~min}$. CGA separations of grape pomace extracts were carried out in a flotation glass column (i.d $5 \mathrm{~cm}$, height: $50 \mathrm{~cm}$ ). The CGA were pumped by a peristaltic pump (Watson Marlow) from the CGA generating container into the column which contained $60 \mathrm{~mL}$ of ethanolic extract of grape pomace. The volume of collapsed CGA and drained liquid phase were measured. The initial extracts of EE and HWE contained $2624 \mathrm{mg}$ $\mathrm{GAE}_{\mathrm{TP}} / \mathrm{L}$ and $1562 \mathrm{mg} \mathrm{GAE} \mathrm{TPI}_{\mathrm{T}} / \mathrm{L}$ respectively. Both fractions were diluted at an appropriate dilution with deionized water for all the tests.

The percentage recovery of a specific compound $(y)$ in the CGA phase (Ry) was calculated based on the differences between the total amount of added $y$ in the feed $\left(M_{y / f e e d}\right)$ and the amount of $y$ measured in the separated liquid phase $\left(M_{y / \text { liq }}\right)$. For some experiments, the 
1 amount of $y$ in the CGA phase was also calculated and the mass balance deviation was within

$210 \%$. The separation factor (SF) was also calculated based on the concentrations of compound

$3 \mathrm{y}$ in the CGA phase $\left([y]_{\mathrm{CGA}}\right)$ and in the liquid phase $\left([y]_{\mathrm{LP}}\right)$ as described in Eq.1:

4

5

6

7

8

9

10

11

12

13

14

15

$$
S F=\frac{[\mathrm{y}]_{\mathrm{CGA}}}{[\mathrm{y}]_{\mathrm{LP}}}
$$

\section{Collagenase and Elastase inhibitory activity of crude extracts and CGA fractions}

The inhibitory activity of gallic acid, grape pomace crude extracts and the CGA fractions against $C$. histolyticum collagenase $(\mathrm{ChC})$ and porcine pancreatic elastase (PPE) were measured spectrophotometrically according to the method used by Wittenauer et al., (10) by using a multi-mode Tecan GENios microplate reader equipped with analysis software Xfluor4 version 4.51 (Salzburg, Austria). Both enzymes were incubated with the extracts and their CGA fractions with relevant substrates (see below). The inhibitory potential of the grape pomace extracts were examined in dilutions so as to establish a dose-dependent curve in order to calculate the half-maximal inhibitory concentrations $\left(\mathrm{IC}_{50}\right)$. Due to the high concentration of polyphenols in the grape pomace extracts, the dilutions of 1:50 to 1:200 with total polyphenolic contents ranging from 52.5 to $7.8 \mathrm{mg}$ GAE/L were applied before being incubated with collagenase and elastase.

Collagenase (ChC) assay: In this assay the enzymatic reaction rate was measured based on the consumption of the substrate peptide FALGPA. Therefore, the slopes of the reaction rates decreased with the increased in extract (inhibitor) concentration. Briefly, $\mathrm{ChC}(0.16 \mathrm{U} / \mathrm{mL})$ and FALGPA $(3 \mathrm{mM})$ were dissolved in $0.05 \mathrm{M}$ tricine buffer containing $0.4 \mathrm{M} \mathrm{NaCl}$ and $0.01 \mathrm{M}$ $\mathrm{CaCl}_{2}$; the $\mathrm{pH}$ was adjusted to 7.5 with $1 \mathrm{M} \mathrm{NaOH}$. The inhibitory activity of the following samples were measured: 
a. Dilutions of ethanolic and hot water grape pomace extracts with water at concentration of (1:50), (1:100) and (1:200) (extract:water).

b. CGA and liquid fractions derived from CGA separations generated from TWEEN20 surfactant.

c. Aqueous solution of gallic acid (43 mg/L, $85 \mathrm{mg} / \mathrm{L}, 128 \mathrm{mg} / \mathrm{L}$ and $170 \mathrm{mg} / \mathrm{L})$.

Briefly, $30 \mu \mathrm{l}$ of the samples (a-c) were incubated with $10 \mu \mathrm{l}$ of ChC solution and $60 \mu \mathrm{l}$ of tricine buffer for 20 mins at $37^{\circ} \mathrm{C}$, after which, $20 \mu \mathrm{l}$ of FALGPA solution was added to initiate the reaction. The reaction rate was measured over 20 mins by measuring the decreased in the absorbance of FALGPA at 340nm. Initial velocities were determined and a dosedependent curve was established. The concentration to inhibit $50 \%$ of the enzyme activity, $\mathrm{IC}_{50}$ values were then determined from the curves. The inhibition activity (\%) was calculated according to Eq.2.

$$
\text { ChC inhibition }(\%)=\frac{\text { Initial velocity } \text { control }_{\text {Initial velocity }}^{\text {sample }}}{\text { Initial velocity }_{\text {control }}} * 100
$$

Elastase (PPE) assay: porcine pancreatic elastase (PPE) inhibitory activity of the individual samples (a-c) was determined spectrophotometrically by using the AAAPVN as the substrate and by monitoring the production of $\mathrm{p}$-nitroaniline at $405 \mathrm{~nm}$ to determine the reaction rate. Briefly, $10 \mu \mathrm{l}$ was taken and loaded into wells together with $100 \mu \mathrm{l}$ of Tris buffer and $30 \mu \mathrm{l}$ of samples. The mixture was incubated for $20 \mathrm{mins}$ at $25^{\circ} \mathrm{C}$. Subsequently, $40 \mu \mathrm{l}$ of the AAAPVN (dissolved in $2 \mathrm{mM}$ Tris buffer at $0.25 \mathrm{mg} / \mathrm{mL}$ ) was added. Since the PPE was performed with AAAPVN as the substrate peptide, the enzyme activity can be calculated from the released of p-nitroaniline as a product, leading to the increased in absorption values. The absorbance was 
1 monitored for 20mins after the addition of AAAPVN and the initial velocities, the inhibitory

2 effect and $\mathrm{IC}_{50}$. The values were calculated as in Eq.2.

\section{Statistical analysis}

All the experiments were performed in triplicate. The data were subjected to the analysis of variance using IBM $®$ SPSS $®$ Statistics 21 software programme where statistical differences were noted. Differences among different treatments were determined using Tukey test. The significance level was defined at $\mathrm{p}<0.05$. The results were reported as means $\pm \mathrm{SD}$.

\section{RESULTS AND DISCUSSIONS}

\section{Ethanolic and hot water extraction}

The chemical composition of the crude grape pomace extracts was determined. In general, the content of total phenols, anthocyanin and protein was higher in EE but sugar was higher in HWE. The total phenolic content in EE was $21.0 \pm 0.1 \mathrm{mg}$ GAE/g of pomace. This value was almost two times higher than in $\operatorname{HWE}(12.5 \pm 0.1 \mathrm{mg}$ GAE/g pomace). A similar result was obtained by the Folin-Ciolcateau method where EE had $22.0 \pm 0.2 \mathrm{mg}$ GAE/g while HWE had $17.0 \pm 0.2 \mathrm{mg}$ GAE/g dry weight pomace. These results closely followed the values obtained in the literature for grape pomace $(17,23)$ and they were higher than those obtained for the Brazilian grape extract as reported by Beres et al. (24). The total monomeric

21 anthocyanins content in EE was $6.6 \pm 0.6 \mathrm{mg} \mathrm{ME} / \mathrm{g}$, almost three times higher than in HWE in HWE than in EE. 


\section{Polyphenol composition of crude grape pomace extracts}

The main composition of the EE and HWE analysed by HPLC is shown in Table 1.

3 Qualitative analysis with LC-MS was also conducted to confirm the identification and/or

4 identify the individual polyphenols in EE and HWE. It must be noted that minor amounts of

5 phenolics may escape from the extraction due to the interaction with dietary fibers, proteins

6 and other polymerised structures (22). In this analysis, fourteen standards of phenols and

7 anthocyanins were analysed against both extracts as not all standards were commercially

8 available. Retention time of standards, MS1 spectra and MS2 fragmentation spectra of the

9 standards were compared to samples'. If the retention time, MS1 and MS2 matched, a confident

10 assignment was given. If only the retention time and MS1 matched, a semi-confident

11 assignment was given. The results of the mass spectrometry data in both positive-ion mode

12 (anthocyanins) and negative-ion mode (phenolic acids, anthoxanthins, stilbenes, flavonols and

13 flavanols) of compounds in the extracts are shown in Table 2. 
1 Table 1: Polyphenol contents (mg/L) of grape pomace extracts and CGA fractions.

\begin{tabular}{|c|c|c|c|c|c|c|}
\hline \multicolumn{7}{|c|}{ Concentration $(\mathrm{mg} / \mathrm{L})$} \\
\hline Compound/Sample & $\mathbf{E E}$ & CGA & $\mathbf{L P}$ & HWE & CGA & LP \\
\hline \multicolumn{7}{|c|}{ Phenolic acids } \\
\hline Gallic acid & $32.3 \pm 2.8$ & $4.1 \pm 0.1$ & $2.2 \pm 0.3$ & $74.5 \pm 6.8$ & $24.9 \pm 1.4$ & $12.2 \pm 2.5$ \\
\hline Caffeic acid & $17.5 \pm 1.4$ & ND & ND & $12.4 \pm 0.3$ & ND & ND \\
\hline Syringic acid & $24.5 \pm 0.9$ & $2.5 \pm 0.1$ & $2.0 \pm 0.1$ & $17.6 \pm 0.4$ & $10.2 \pm 3.9$ & $7.4 \pm 1.8$ \\
\hline Chlorogenic acid & $7.1 \pm 0.4$ & ND & ND & $21.2 \pm 2.3$ & ND & $3.5 \pm 2.5$ \\
\hline 4-hydroxy benzoic acid & ND & ND & ND & $6.9 \pm 0.1$ & ND & ND \\
\hline Total phenol acids & $81.3 \pm 5.3$ & $6.6 \pm 0.1$ & $4.2 \pm 0.1$ & $132.6 \pm 9.1$ & $35.1 \pm 5.3$ & $23.1 \pm 6.8$ \\
\hline \multicolumn{7}{|c|}{ Flavonols } \\
\hline Resveratrol & $\begin{array}{l}36.80 \pm \\
3.90\end{array}$ & ND & ND & ND & ND & ND \\
\hline Quercetin & $\begin{array}{l}108.40 \pm \\
5.10\end{array}$ & $31.1 \pm 0.5$ & $\begin{array}{l}17.4 \pm \\
0.7\end{array}$ & $29.6 \pm 0.3$ & ND & ND \\
\hline Kaempferol & $\begin{array}{l}16.10 \pm \\
1.50\end{array}$ & $6.5 \pm 0.2$ & $3.9 \pm 0.7$ & $67.5 \pm 0.9$ & $23.5 \pm 0.1$ & $24.4 \pm 0.1$ \\
\hline \multirow[t]{2}{*}{ Total flavonols } & $\begin{array}{l}161.30 \pm \\
10.50\end{array}$ & $37.6 \pm 0.7$ & $\begin{array}{l}21.3 \pm \\
1.4\end{array}$ & $97.1 \pm 1.1$ & $23.5 \pm 0.1$ & $24.4 \pm 0.1$ \\
\hline & & Flavanols & & & & \\
\hline Catechin & $3.1 \pm 0.2$ & ND & ND & $30.9 \pm 0.1$ & $9.5 \pm 0.3$ & ND \\
\hline Epicatechin & $28.7 \pm 4.0$ & ND & ND & $18.3 \pm 0.6$ & ND & ND \\
\hline Total flavanols & $31.8 \pm 4.2$ & ND & ND & $49.2 \pm 0.6$ & $9.5 \pm 0.3$ & ND \\
\hline \multicolumn{7}{|c|}{ Anthocyanins } \\
\hline Delphinidin 3-o-glucoside & $\begin{array}{l}72.2 \pm \\
15.5\end{array}$ & $36.0 \pm 6.3$ & $\begin{array}{l}17.6 \pm \\
7.8\end{array}$ & $29.7 \pm 0.2$ & $1.9 \pm 0.6$ & $1.0 \pm 0.9$ \\
\hline Petunidin 3-o-glucoside & $\begin{array}{l}33.5 \pm \\
16.3\end{array}$ & $17.4 \pm 7.5$ & $9.4 \pm 0.3$ & $11.6 \pm 0.4$ & $1.1 \pm 0.4$ & $0.7 \pm 0.5$ \\
\hline Cyanidin 3-o-glucoside & $13.8 \pm 2.1$ & $8.2 \pm 0.3$ & $4.0 \pm 0.2$ & $4.9 \pm 0.1$ & $0.2 \pm 0.3$ & $0.1 \pm 0.2$ \\
\hline Malvidin 3-o-glucoside & $\begin{array}{l}85.0 \pm \\
17.2\end{array}$ & $41.2 \pm 0.1$ & $\begin{array}{l}23.9 \pm \\
0.3\end{array}$ & $30.2 \pm 0.1$ & $3.7 \pm 1.5$ & $2.4 \pm 1.3$ \\
\hline Total anthocyanins & $\begin{array}{l}204.5 \pm \\
51.1\end{array}$ & $\begin{array}{l}102.8 \pm \\
13.9\end{array}$ & $\begin{array}{l}54.9 \pm \\
7.9\end{array}$ & $76.5 \pm 0.5$ & $7.0 \pm 2.6$ & $4.2 \pm 2.8$ \\
\hline Total & $\begin{array}{l}478.9 \pm \\
71.0\end{array}$ & $\begin{array}{l}147.0 \pm \\
14.8\end{array}$ & $\begin{array}{l}80.44 \pm \\
9.33\end{array}$ & $\begin{array}{l}355.2 \pm \\
11.4\end{array}$ & $75.0 \pm 8.0$ & $51.7 \pm 9.6$ \\
\hline
\end{tabular}

2 ND: not detected; EE: ethanol extract; HWE: hot water extract; CGA: CGA phase; LP: liquid phase.

3 Values represent mean \pm standard deviation $(\mathrm{n}=3)$.

4 
1 Table 2: LC-MS data of phenolic compounds extracted from grape pomace

\begin{tabular}{|c|c|c|c|c|c|c|}
\hline No. & Compound & $\begin{array}{l}\text { Retention } \\
\text { time (min) }\end{array}$ & $m / z$ & $\begin{array}{l}M S / M S \\
\text { fragments } \\
m / z\end{array}$ & $E E$ & $H W E$ \\
\hline & \multicolumn{6}{|c|}{$\begin{array}{l}\text { Phenolic acids } \\
{[\mathrm{M}-\mathrm{H}]-}\end{array}$} \\
\hline 1 & * Gallic acid & 3.2 & 169.0142 & 125 & $\sqrt{ }$ & $\sqrt{ }$ \\
\hline 2 & Caftaric acid & 6.5 & 311.0409 & $179 / 135$ & & $\sqrt{ }$ \\
\hline 3 & $\begin{array}{l}* \text { p-hydroxybenzoic } \\
\text { acid }\end{array}$ & 7.3 & 137.0244 & 93 & $\sqrt{ }$ & $\sqrt{ }$ \\
\hline 4 & * Caffeic acid & 10.6 & 179.0350 & 135 & $\sqrt{ }$ & $\sqrt{ }$ \\
\hline 5 & * Ferulic acid & 10.8 & 193.0506 & 134 & $\sqrt{ }$ & $\sqrt{ }$ \\
\hline 6 & * Fertaric acid & 10.9 & 325.0565 & 193 & $\sqrt{ }$ & $\sqrt{ }$ \\
\hline 7 & Syringic acid & 11.4 & 197.0455 & $153 / 182$ & $\sqrt{ }$ & $\sqrt{ }$ \\
\hline \multicolumn{7}{|c|}{$\begin{array}{c}\text { Anthoxanthins and Stilbenes } \\
{[M-H]-}\end{array}$} \\
\hline 8 & Procyanidin B1 & 7.4 & 577.1351 & $407 / 425$ & $\sqrt{ }$ & $\sqrt{ }$ \\
\hline 9 & * Catechin & 8.9 & 289.0718 & 245 & $\sqrt{ }$ & $\sqrt{ }$ \\
\hline 10 & * Procyanidin B2 & 10.1 & 577.1351 & $407 / 425$ & $\sqrt{ }$ & $\sqrt{ }$ \\
\hline 11 & * Epicatechin & 13.1 & 289.0718 & 245 & $\sqrt{ }$ & $\sqrt{ }$ \\
\hline 12 & * Epicatechin gallate & 19.6 & 441.0827 & 289 & & $\sqrt{ }$ \\
\hline 13 & * trans-resveratrol & 23.1 & 227.0714 & 185 & $\sqrt{ }$ & $\sqrt{ }$ \\
\hline 14 & * Quercetin & 20.4 & 301.0354 & $151 / 179$ & $\sqrt{ }$ & $\sqrt{ }$ \\
\hline 15 & Kaempferol & 27.9 & 285.0405 & 257 & $\sqrt{ }$ & $\sqrt{ }$ \\
\hline 16 & $\begin{array}{l}\text { Quercetin 3-o- } \\
\text { galactoside }\end{array}$ & 19.8 & 463.0882 & 301 & $\sqrt{ }$ & $\sqrt{ }$ \\
\hline 17 & $\begin{array}{l}\text { Quercetin 3-o- } \\
\text { glucoside }\end{array}$ & 20.4 & 463.0882 & 301 & $\sqrt{ }$ & $\sqrt{ }$ \\
\hline \multicolumn{7}{|c|}{$\begin{array}{l}\text { Anthocyanins } \\
{[M]+}\end{array}$} \\
\hline 18 & $\begin{array}{l}\text { *Delphinidin 3-o- } \\
\text { glucoside }\end{array}$ & 8.52 & 465.1028 & 303 & $\sqrt{ }$ & $\sqrt{ }$ \\
\hline 19 & $\begin{array}{l}\text { *Cyanidin 3-o- } \\
\text { glucoside }\end{array}$ & 10.9 & 449.1078 & 287 & $\sqrt{ }$ & $\sqrt{ }$ \\
\hline 20 & $\begin{array}{l}\text { *Petunidin 3-o- } \\
\text { glucoside }\end{array}$ & 12.4 & 479.1184 & 317 & $\sqrt{ }$ & $\sqrt{ }$ \\
\hline 21 & $\begin{array}{l}\text { *Malvidin 3-o- } \\
\text { glucoside }\end{array}$ & 14.1 & 493.1341 & 331 & $\sqrt{ }$ & $\sqrt{ }$ \\
\hline 22 & $\begin{array}{l}\text { Peonidin 3-o- } \\
\text { glucoside }\end{array}$ & 14.7 & 463.1235 & 301 & $\sqrt{ }$ & $\sqrt{ }$ \\
\hline 23 & $\begin{array}{l}\text { Delphinidin 3-o- } \\
\text { acetylglucoside }\end{array}$ & 16.3 & 507.1133 & 303 & $\sqrt{ }$ & $\sqrt{ }$ \\
\hline 24 & $\begin{array}{l}\text { Cyanidin 3-o- } \\
\text { acetylglucoside }\end{array}$ & 18.7 & 491.1184 & 287 & $\sqrt{ }$ & $\sqrt{ }$ \\
\hline 25 & $\begin{array}{l}\text { Malvidin 3-o- } \\
\text { acetylglucoside }\end{array}$ & 21.5 & 535.1446 & 331 & $\sqrt{ }$ & $\sqrt{ }$ \\
\hline 26 & $\begin{array}{l}\text { Peonidin 3-o- } \\
\text { acetylglucoside }\end{array}$ & 21.6 & 505.1341 & 301 & $\sqrt{ }$ & $\sqrt{ }$ \\
\hline
\end{tabular}




\begin{tabular}{|c|c|c|c|c|c|}
\hline 27 & $\begin{array}{l}\text { Cyanidin 3-o-p- } \\
\text { coumaroylglucoside }\end{array}$ & 23.1 & 595.1446 & 287 & $\sqrt{ }$ \\
\hline 28 & $\begin{array}{l}\text { Petunidin 3-o-p- } \\
\text { coumaroylglucoside }\end{array}$ & 23.9 & 625.1552 & 317 & $\sqrt{ }$ \\
\hline 29 & $\begin{array}{l}\text { Peonidin 3-o-p- } \\
\text { coumaroylglucoside }\end{array}$ & 25.1 & 609.1603 & 301 & $\sqrt{ }$ \\
\hline 30 & $\begin{array}{l}\text { Malvidin 3-o-p- } \\
\text { coumaroylglucoside }\end{array}$ & 25.6 & 639.1708 & 331 & $\sqrt{ }$ \\
\hline
\end{tabular}

A total of 30 phenolic compounds were present in both extracts. Among these, 7 phenolic 6 acids, 10 anthoxanthins and stilbenes and 13 anthocyanins were detected in both extracts. All 7 anthocyanins detected were of monoglucoside (glu), acetyl and p-coumaroyl derivatives of 8 delphinidin (DEL), cyanidin (CYA), petunidin (PET), peonidin (PEO) and malvidin (MAL).

9 Out of these 30 compounds, 15 were given confident assignment as the retention times, MS1 and MS2 matched with the standards. These compounds were gallic acid, p-hydroxybenzoic 11 acid, caffeic acid, ferulic acid, fertaric acid, catechin, procyanidin B2, epicatechin, epicatechin 12 gallate, trans-resveratrol, quercetin, delphinidin 3-o-glucoside, cyanidin 3-o-glucoside, 13 petunidin 3-o-glucoside and malvidin 3-o-glucoside. The MS2 mode was used to provide information on the aglycone and its corresponding sugar due to the observed $\mathrm{m} / \mathrm{z}$ fragmentation values (303 for DEL; 287 for CYA; 317 for PET; 301 for PEO; and 331 for MAL) which were matched to those reported in the literature (22). In this analysis, quercetin 3-o-glucoside and quercetin 3-o-galactoside have the same MS1 and MS2, therefore their retention times are the same; thus, differentiation of these polyphenols cannot be made. In the case of anthocyanins, all anthocyanins and derivatives were present in both EE and HWE. However, differences were noted in the composition of phenolic acids and anthoxanthins/stilbenes between both extracts where the EE was lacking the presence of caftaric acid and epicatechin gallate.

In general, both extracts had the same type of compounds present but interestingly they differed in their composition. This is particularly clear when the mass percentage of groups of 
1 polyphenols (eg: phenolic acids) is calculated from data in Table 1. For example, phenolic

2 acids were present at higher proportion in the HWE (37\%) than in the EE (17\%); in both

3 extracts gallic acid was the predominant phenolic acid. Similarly flavanols where at higher 4 proportion in HWE (14\%) than in EE (7\%). However the composition of flavonols was similar 5 in both extracts, (34\% and $27 \%$ in EE and HWE respectively) but quercetin was predominant 6 in EE and Keampferol in HWE. The anthocyanins composition was higher in EE (43\%), than 7 in HWE (22\%). However, with regards to the collagenase and elastase inhibitory activities and 8 their relationship to polyphenols composition (see below) phenolic acids, flavonols and 9 flavanols were the most relevant as anthocyanins have not been related to these activities.

\section{Separation of polyphenols from crude grape extracts by CGA}

Table 3 shows the recovery (\%) and separation factor (SF) of the CGA separation from EE and HWE. Very similar recoveries of phenols and anthocyanins were obtained from both extracts. Generally, the recovery of compounds was higher in EE than in HWE. A separation factor higher than one indicated higher affinity of the compound for the CGA phase than the liquid phase. This was the case for all compounds in both extracts although higher SF's were obtained for EE. The selecvity of the separation in relation to both protein and sugar was low as these were also preferentially separated into the CGA phase although the SF of sugar from HWE was lower than one. The low ratio value of $\mathrm{V}_{\mathrm{LP}} / \mathrm{V}_{\mathrm{CGA}}$ (ie: low volume of liquid drained in relation to volume of CGA) was an indication of a stable CGA which might be due to the presence of other compounds (glucose and proteins) which could increase the viscosity of the liquid in the continuous phase and hence increased the stability of the CGA (15). It is also important to highlight that some aggregates were observed in the CGA phase which did not completely solubilise during analysis, hence this would probably lead to an underestimation of the net recovery. Overall, the recovery results were in agreement with our previous work (15). 
2 Table 3: Recovery efficiency (\%) and separation factor (SF) by CGA separations of EE and HWE

\begin{tabular}{l|l|l} 
Extract & EE & HWE \\
\hline $\mathbf{V}_{\mathbf{C G A}} / \mathbf{V}_{\text {feed }}$ & 16 & 16 \\
$\mathbf{V}_{\mathbf{L P}} / \mathbf{V}_{\mathbf{C G A} \text {-phase }}$ & 0.50 & 0.55 \\
\hline Recovery (\%) & & \\
GAE $_{\mathrm{FI}}$ & $83.45^{\mathrm{bc}}$ & $85.87^{\mathrm{c}}$ \\
GAE $_{\text {TPI }}$ & $79.40^{\mathrm{b}}$ & $71.39^{\mathrm{ab}}$ \\
ME & $84.99^{\mathrm{c}}$ & $77.39^{\mathrm{b}}$ \\
Glucose & $71.74^{\mathrm{a}}$ & $68.91^{\mathrm{a}}$ \\
Protein & $85.86^{\mathrm{c}}$ & $66.45^{\mathrm{a}}$ \\
\hline SF & & \\
GAE & & $1.31^{\mathrm{b}}$ \\
GAE & $4.71^{\mathrm{c}}$ & $1.20^{\mathrm{b}}$ \\
ME & $1.89^{\mathrm{b}}$ & $1.31^{\mathrm{b}}$ \\
Glucose $_{\text {Protein }}$ & $1.47^{\mathrm{a}}$ & $1.34^{\mathrm{b}}$ \\
\hline & $1.65^{\mathrm{a}}$ & $0.87^{\mathrm{a}}$ \\
\hline
\end{tabular}

$3 \mathrm{GAE}_{\mathrm{FI}}$, Gallic acid equivalent (Folin-Cioulcateau index; $\mathrm{GAE}_{\mathrm{TPI},}$ Gallic acid equivalent (total phenol index); $\mathrm{ME}$,

4 Malvidin glucoside equivalent; $\mathrm{V}_{\mathrm{LP}} / \mathrm{V}_{\mathrm{CGA} \text {-phase, }}$, ratio of volume of liquid phase to the volume of CGA phase. Same 5 superscript letters in the same column (for each recovery and SF) indicates means were not statiscally different 6 ( $p>0.05)$ according to ANOVA ( $\mathrm{n}=3)$.

\section{$8 \quad$ Collagenase and elastase inhibitory activity}

9 The ethanolic (EE) and hot water extracts (HWE) of grape pomace were tested for their

$10 \mathrm{ChC}$ and PPE inhibitory activity. Collagen, which occupies around 70-80\% of the skin weight

11 is known to provide structural integrity (6). Due to skin ageing, collagen is rapidly degraded

12 by the action of collagenase. As shown in Figures 2(A) and 2(B), the grape pomace extracts

13 showed a linear dose-dependant relationship with inhibitory activities. From these dose-

14 dependent relationships, $\mathrm{IC}_{50}$ values were calculated to be $35.4 \mathrm{mg} / \mathrm{L}$ (HWE), $78.8 \mathrm{mg} / \mathrm{L}$ (EE)

15 and 130mg/L (gallic acid). The maximum inhibitory activity measured for EE was 34\%,

16 therefore above this activity (up to 50\%) a linear relationship with concentration was assumed

17 in order to determine the $\mathrm{IC}_{50}$. 

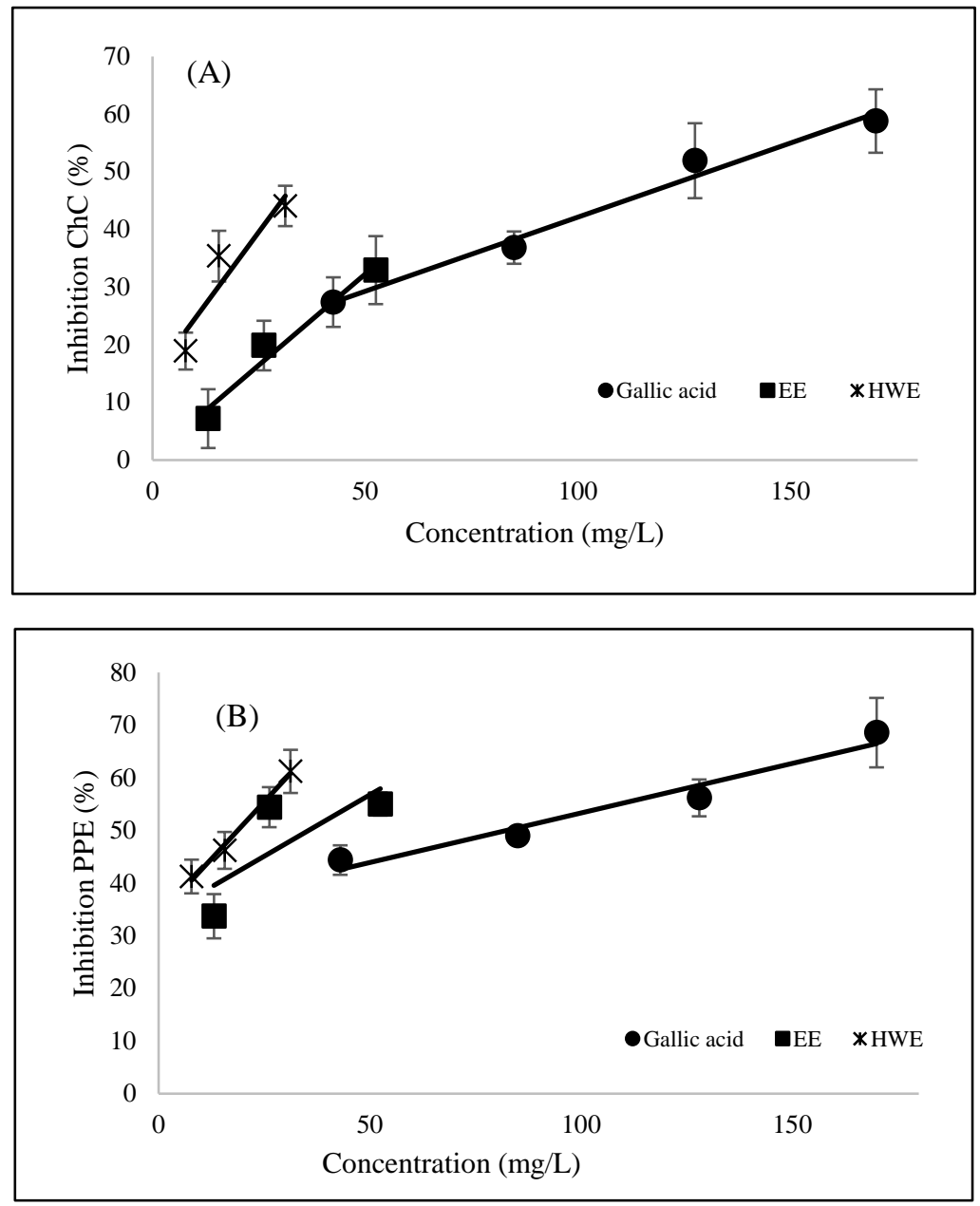

1 Figure 2: Dose dependent inhibition of collagenase (A) and elastase (B) activity by gallic acid, ethanol 2 extract (EE) and hot water extract (HWE) $(n=3)$.

3

The same trend was observed for PPE inhibitory activity. Elastin is an insoluble fibrous

5 protein which occupies only $2-4 \%$ of the skin dermis weight but plays a vital role ensuring the

6 elasticity of the skin (6). Based on the $\mathrm{IC}_{50}$ results, HWE $(18.7 \mathrm{mg} / \mathrm{L})$ had the highest potency

7 as compared to EE (35.5mg/L) and galic acid (82.0mg/L). Similar IC $\mathrm{I}_{50}$ value was obtained with

8 the methanolic extract of grape pomace $(14.7 \mathrm{mg} / \mathrm{L})$ which may suggests comparable

9 polyphenol composition (10).

10 The higher inhibitory activity of HWE than EE against collagenase and elastase can be

11 explained by the differences in polyphenols composition. The phenolic acids such as gallic acid

12 and chlorogenic acid in HWE which account for $37 \%$ of total polyphenols could have a 
1 pronounced effect on the inhibitory activities. Gallic acid, a low molecular weight hydrophilic

2 compound could play an important part in the observed activity by accessing the active centre

3 site of the elastase and blocking the binding of substrates to this site (10). However, given that

4 the potency of the extract was superior than that of the gallic acid alone (Table 4), it is clear

5 that other components also may contribute to the activity, perhaps in a synergistic manner.

6 Chlorogenic acid, for example, which is a derivative of cinnamic acid, could also contribute as

7 it is well known for its potent antioxidant and anti-inflammatory activities (25). Moreover, the

8 catechin and epicatechin which were present at high proportion in HWE (14\%) could interact

9 with the elastase by hydrophobic interactions, causing conformational changes of elastase and

10 thus increasing the inhibitory activity (7). On the other hand, EE had high composition of

11 flavonols, particularly quercetin and resveratrol but they are larger molecules with lower solubility in water than the phenolic acids which could possibly limit their activity.

14 Collagenase and elastase inhibitory activity of CGA fractions in relation to polyphenolic 15 profile

In order to determine the most active fractions after separation by CGA, CGA and liquid 17 phases from both EE and HWE were tested for ChC and PPE. The inhibitory activities against 18 ChC ad PPE are shown in Figures 3(A) and (B), respectively. Contrary to the crude extracts, 19 EE fractions demonstrated higher activity than HWE fractions, CGA-EE had $67 \%$ collagenase inhibitory activity and CGA-HWE 55\%; the liquid phases had 60\% and $46 \%$ activity, 21 respectively. This small difference in activity between the liquid and CGA phases can be explained based on their polyphenol composition (Table 1). 

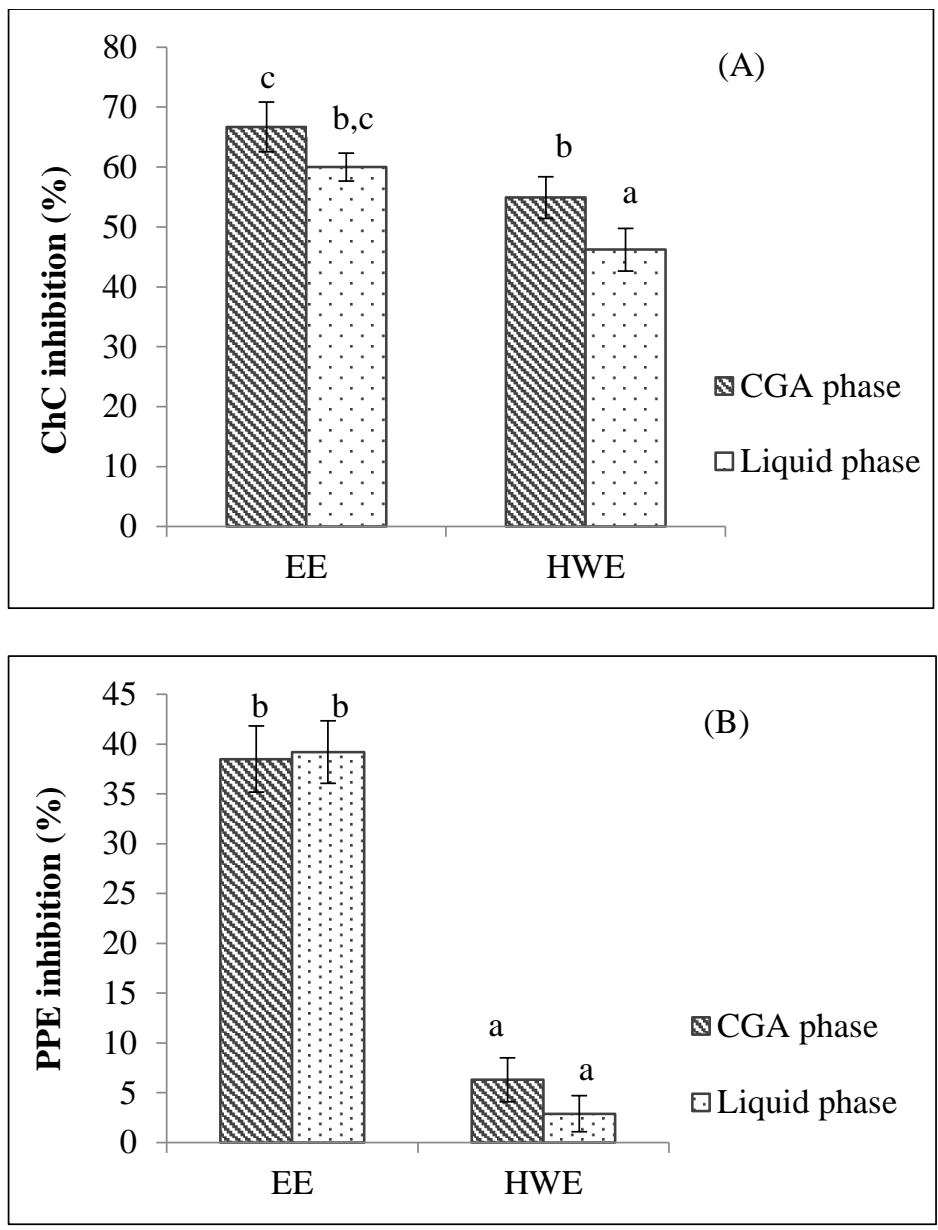

1 Figure 3: Anti-collagenase activity (A) and anti-elastase activity (B) of CGA fractions from EE and

2 HWE. Bars are means \pm standard deviation of three determinations $(n=3)$. Same superscript letters 3 indicates means with no significant difference $(p>0.05)$ according to ANOVA $(n=3)$.

6 the same (mass percentages of phenolic acids over total phenols were $47 \%$ and $45 \%$

7 respectively) and for flavonols composition was higher in the liquid phase (31\% in CGA and $847 \%$ in liquid phase). The same trend was noted in CGA-EE and LP-EE where phenolic acids 9 and flavonols compositon was very similar in both fractions (4.5 and 5.2\% phenolic acids in 10 CGA and LP respectively and $26 \%$ flavonols in both fractions). This similarity in compositon 11 supports the insignificant differences in inhibitory activities of these fractions against both 12 enzymes. Kaempferol was found at high concentration in both CGA-HWE and LP-HWE (23.5 and $24.4 \mathrm{mg} / \mathrm{L}$ respectively) but in the case of CGA-EE, the most predominant flavonol was 
1 quercetin $(31.1 \mathrm{mg} / \mathrm{L})$. These compounds could possibly be the main contributors to the

2 inhibitory activities observed whereby the hydroxyl group in C-3 might played a role in

3 conferring the inhibitory activity (9). Moreover, the high content of gallic acid in CGA-HWE

$4 \quad(24.9 \mathrm{mg} / \mathrm{L})$ and in LP-HWE $(12.2 \mathrm{mg} / \mathrm{L})$ could also be important for the ChC inhibitory

5 activity. The hydroxyl group from gallic acid could act as a hydrogen bond acceptor/donors

6 with the hydroxyl, amino or carboxyl groups of the collagenase's side chain functional groups

7 which can alter its structure, while the benzene rings of the polyphenols can form hydrophobic

8 interactions with collagenase $(8,10)$.

9 The differences in inhibitory activity against PPE between the LP and CGA fractions (Fig 3B)

10 could be explained based on the differences in composition (see above). On the other hand the

11 much higher activity in the EE fractions than in the HWE fractions could not be clearly

12 explained in terms of differences in composition of groups of polyphenols but individual

13 polyphenols. For example, quercetin was predominantly present in the CGA-EE whilst none

14 was detected in the CGA-HWE. This suggests that quercetin is a key compound responsible

15 for PPE inhibition. Quercetin could possibly alter the specificity of the elastase substrate by interacting with subsite of MMP-9 active site (26).

17 Table 4: Inhibitory efficiency $\left(\% / \mathrm{mg} \mathrm{GAE}_{\mathrm{FI}} \mathrm{L}^{-1}\right)$ of crude extracts and CGA-separated fractions

\begin{tabular}{llllllll}
\hline Extract/Activity & EE & CGA-EE & LP-EE & HWE & CGA-HWE & LP-HWE & Gallic acid \\
\hline ChC & 0.63 & 2.43 & 2.18 & 1.41 & 2.45 & 0.37 & 0.38 \\
\hline PPE & 1.41 & 1.40 & 1.43 & 2.67 & 0.28 & 0.02 & 0.61 \\
\hline
\end{tabular}

18

In order to assess if any of the fractions had been preferentially enriched with the most

21 active polyphenols the activity potency had to be determined. However, these fractions showed 22 poor dose-dependency relationship (data not shown) and the IC50 could not be determined. 
1 Therefore, the inhibitory potency of CGA fractions was expressed as inhibitory efficiency

2 which is the activity in relation to the total phenols content (\% / mg GAE $\left.\mathrm{FI}^{-1}\right)$ (Table 4). The

3 CGA-EE fraction was found to be about four times more efficient than its crude extract and

4 over six times more efficient than gallic acid in relation to $\mathrm{ChC}$ inhibitory activity. However

5 the efficiency of both CGA and LP fractions was almost the same which is in agreement with

6 results in Fig 3. Interestingly the efficiency in CGA-HWE was seven times higher than in LP

7 and almost double that in the raw extract (HWE). Moreover the efficiency of the CGA

8 fractions of both raw extracts was six times higher than gallic acid's which suggests that the

9 inhibition of these enzymes could be the result of synergistic activity of different polyphenols.

10 This has been observed in a formulation of four combined super fruits extract (Ginkgo biloba,

11 Punica granatum, Ficus carica, and Morus alba) against collagenase (27).

In the case of PPE inhibitory activity, no increase in efficiency was noted for the

$13 \mathrm{CGA} / \mathrm{LP}$ fractions of EE and the efficiency of the HWE decreased after CGA separation. The

14 inhibitory efficiencies of the raw extracts were superior to that of pure gallic acid.

From results above it could be hypothesised that TWEEN20 might play a role in facilitating the delivery of the polyphenols to the target site of the collagenase. This explained why the efficieny of the CGA-EE increased susbstantially as compared to the crude extract's and it was comparable to that of CGA-HWE. It is also worth mentioning that the surfactant did not inhibit or activate both $\mathrm{ChC}$ and PPE (data not shown) hence, the inhibitory activities were solely due to the action of polyphenols in the fractions. Non-ionic surfactants were known to cause the least irritating effect to skin compared to anionic surfactants hence they were preferred for inclusion in many skin care products (28). Moreover, surfactants in general are known to alter the skin permeation by forming non-specific hydrophobic interactions involving the alkyl chains of the surfactant and the hydrophobic regions of the keratin in stratum corneum (30). Most studies about non-ionic surfactants and biological activities revealed that the C12 
1 alkyl chain was the most important character in terms of perturbation of the membrane which

2 explained the surfactant solubility and partitioning (31). Although most studies revealed that

3 their interactions with non-ionic surfactants did not alter skin permeation to a significant level,

4 enhancement has been noted in some studies whereby penetration of lidocaine (a type of drug)

5 significantly increased through hairless mouse skin with TWEEN20 and TWEEN60 (28).

\section{CONCLUSIONS}

The extraction of polyphenols from grape pomace by ethanol and hot water led to crude

9 extracts with different polyphenol compositions and this also resulted in differences in collagenase and elastase inhibitory activity. Phenolic acids were present at higher proportion in the HWE (37\%) than in the EE (17\%) which suggested their important role in the inhibition. HWE was the most efficient at inhibiting both collagenase and elastase and both EE and HWE were superior to gallic acid. Further extraction by CGA led to higher inhibitory efficiency against collagenase although there was no difference in efficiency between the separated phases for EE but there was for HWE. Gallic acid was the main component of the CGA-HWE but other polyphenols (eg: kaempferol) must have contributed also to its potency as this fraction inhibited collagenase over six times more efficiently than gallic acid. The CGA-EE fraction was found to be about four times more efficient than its crude extract and over six times more efficient than gallic acid in collagenase's inhibition; quercetin was found to be the major polyphenol in this fraction. These results suggested that although quercetin was highly insoluble in water and had high molecular weight, TWEEN20 helped to improve its solubility and therefore facilitated its delivery to the enzyme. Therefore, CGA separation led to fractions enriched in active polyphenols with enhanced collagenase inhibitory activity in both CGA and liquid phases. Although the polyphenols composition in CGA and liquid phases in both extracts 
1 were very similar, and hence their inhibitory activities, it must be stressed that further separation with CGA led to CGA fractions with less sugar and protein (and ethanol when applied to the ethanolic extract) which can be an advantage in terms of formulation. It should be noted that the concentration of these polyphenols in the CGA fractions were topically relevant (generally between $25-100 \mu \mathrm{M}$ ). Moreover the surfactant in these fractions could act as a carrier and solubilising agent to enhance the permeation of polyphenols across the skin. Therefore, the surfactant rich solution may provide an optimum media that could facilitate the permeation of the polyphenols through the skin. This research shows the potential of CGA to revalorise the grape marc and to obtain an extract with potential in cosmetics applications.

\section{REFERENCES}

1. Menaa F, Menaa A, Tréton J. Polyphenols against Skin Aging. Polyphenols Hum Heal

2. Haslam E, Cai Y. Plant polyphenols (vegetable tannins): gallic acid metabolism. Nat Dis. 2013;1:819-30.

Prod Rep. 1994;11(1):41-66.

3. Perona JS, Cabello-Moruno R, Ruiz-Gutierrez V. The role of virgin olive oil components in the modulation of endothelial function. J Nutr Biochem [Internet]. 2006;17(7):429-45. Available from: http://www.ncbi.nlm.nih.gov/pubmed/16481154

4. Chiu AE, Chan JL, Kern DG, Kohler S, Rehmus WE, Kimball AB. Double-blinded, placebo-controlled trial of green tea extracts in the clinical and histologic appearance of photoaging skin. Dermatol Surg [Internet]. 2005;31(7 Pt 2):855-60; discussion 860. Available from: http://www.ncbi.nlm.nih.gov/pubmed/16029678

5. Türkoğlu M, Uğurlu T, Gedik G, Yılmaz AM, Süha Yalçin A. In vivo evaluation of black and green tea dermal products against UV radiation. Drug Discov Ther [Internet]. 2010;4(5):362-7. Available from: http://www.ncbi.nlm.nih.gov/pubmed/22491240

6. Hong Y-H, Jung EY, Noh DO, Suh HJ. Physiological effects of formulation containing tannase-converted green tea extract on skin care: physical stability, collagenase, elastase, and tyrosinase activities. Integr Med Res [Internet]. Korea Institute of Oriental Medicine; 2014;3(1):25-33. Available from: http://www.sciencedirect.com/science/article/pii/S2213422013000991

7. Wahab NA, Rahman RA, Ismail A, Mustafa S, Hashim P. Assessment of Antioxidant Capacity, Anti-collagenase and Anti-elastase Assays of Malaysian Unfermented Cocoa Bean for Cosmetic Application. Nat Prod Chem Res [Internet]. 2014;2(2). Available from: http://dx.doi.org/10.4172/2329-6836.1000132 
8. Madhan B, Krishnamoorthy G, Rao JR, Nair BU. Role of green tea polyphenols in the inhibition of collagenolytic activity by collagenase. Int $\mathrm{J}$ Biol Macromol. 2007;41(1):16-22.

9. Sin BY, Kim HP. Inhibition of Collagenase by Naturally-Occurring Flavonoids. Arch Pharm Res [Internet]. 2005;28(10):1152-5. Available from: http://apr.psk.or.kr

10. Wittenauer J, Mäckle S, Sußmann D, Schweiggert-weisz U, Carle R. Inhibitory effects of polyphenols from grape pomace extract on collagenase and elastase activity. Fitoterapia [Internet]. Elsevier B.V.; 2015;101:1-9. Available from: http://dx.doi.org/10.1016/j.fitote.2015.01.005

11. Zillich O V, Schweiggert-Weisz U, Hasenkopf K, Eisner P, Kerscher M. Release and in vitro skin permeation of polyphenols from cosmetic emulsions. Int J Cosmet Sci [Internet]. 2013;35(5):491-501. Available from: http://dx.doi.org/10.1111/ics.12072

12. Löf D, Schillèn K, Nilsson L. Flavonoids: Precipitation kinetics and interaction with surfactant micelles. J Food Sci. 2011;76(3):35-9.

13. Yutani R, Morita S, Teraoka R, Kitagawa S. Distribution of Polyphenols and a Surfactant Component in Skin during Aerosol OT Microemulsion-Enhanced Intradermal Delivery. Chem Pharm Bull. 2012;60(8):989-94.

14. Williams AC, Barry BW. Penetration enhancers. Adv Drug Deliv Rev. 2004;56(5):60318.

15. Spigno G, Amendola D, Dahmoune F, Jauregi P. Colloidal gas aphrons based separation process for the purification and fractionation of natural phenolic extracts. Food Bioprod Process [Internet]. Institution of Chemical Engineers; 2015;94:434-42. Available from: http://dx.doi.org/10.1016/j.fbp.2014.06.002

16. Spigno G, Jauregi P. Recovery of Gallic Acid with Colloidal Gas Aphrons (CGA). Int J Food Eng [Internet]. 2005;1(4):1-10. Available from: http://www.degruyter.com/view/j/ijfe.2005.1.4/ijfe.2005.1.4.1038/ijfe.2005.1.4.1038.x $\mathrm{ml}$

17. Amendola D, De Faveri DM, Spigno G. Grape marc phenolics: Extraction kinetics, quality and stability of extracts. J Food Eng. 2010;97:384-92.

18. Singleton VL, Rossi JAJ. Colorimetry of total phenolics with acid reagents. Am J Enol Vitic. 1965;16:144-58.

19. Lee J, Rennaker C, Wrolstad RE. Correlation of two anthocyanin quantification methods: HPLC and spectrophotometric methods. Food Chem. 2008;110(3):782-6.

20. Smith PK, Krohn RI, Hermanson GT, Mallia AK, Gartner FH, Provenzano MD, et al. Measurement of protein using bicinchoninic acid. Anal Biochem. 1985;150:76-85.

21. Dubois M, Gilles KA, Hamilton JK, Rebers PA, Smith F. Colorimetric Method for Determination of Sugars and Related Substances. Anal Chem. 1956;28(3):350-6.

22. Kammerer D, Claus A, Carle R, Schieber A. Polyphenol Screening of Pomace from Red and White Grape Varieties (Vitis vinifera L.) by HPLC-DAD-MS/MS. J Agric Food Chem. 2004;52:4360-7.

23. Tseng A, Zhao Y. Wine grape pomace as antioxidant dietary fibre for enhancing nutritional value and improving storability of yogurt and salad dressing. Food Chem. 
2013;138(1):356-65.

24. Beres C, Simas-Tosin FF, Cabezudo I, Freitas SP, Iacomini M, Mellinger-Silva C, et al. Antioxidant dietary fibre recovery from Brazilian Pinot noir grape pomace. Food Chem [Internet]. Elsevier Ltd; 2016;201:145-52. Available from: http://www.sciencedirect.com/science/article/pii/S0308814616300383

25. Farah A, Monteiro M, Donangelo CM, Lafay S. Chlorogenic Acids from Green Coffee Extract are Highly Bioavailable in Humans 1 , 2. J Nutr. 2008;(July):2309-15.

26. Saragusti AC, Ortega MG, Cabrera JL, Estrin DA, Marti MA, Chiabrando GA. Inhibitory effect of quercetin on matrix metalloproteinase 9 activity Molecular mechanism and structure-activity relationship of the flavonoid-enzyme interaction. Eur J Pharmacol [Internet]. Elsevier B.V.; 2010;644(1-3):138-45. Available from: http://dx.doi.org/10.1016/j.ejphar.2010.07.001

27. Ghimeray AK, Jung US, Lee HY, Kim YH, Ryu EK, Chang MS. In vitro antioxidant, collagenase inhibition, and in vivo anti-wrinkle effects of combined formulation containing Punica granatum, Ginkgo biloba, Ficus carica, and Morus alba fruits extract. Clin Cosmet Investig Dermatol. 2015;

28. Zatz JL, Lee B. Skin Penetration Enhancement by Surfactants. In: Rieger MM, Rhein LD, editors. 2nd ed. New York: Marcel Dekker; 1997. p. 501-17.

\section{Acknowledgement}

21 The authors would like to thank the Ministry of Education Malaysia (MOE) and Universiti 22 Malaysia Terengganu (UMT) for their financial support. The authors are also grateful to winery in Northern Italy for providing the grape pomace. 